\title{
Influence of Solvent and Thickness Variation on the Performance of Poly(Vinylidene Fluoride-co-hexafluoropropylene) Polymer Membrane
}

\author{
Usaid ur Rehman Farooqui, Abdul Latif Ahmad* and Noorashrina Abdul Hameed \\ School of Chemical Engineering, Universiti Sains Malaysia, Engineering Campus, \\ 14300 Nibong Tebal, Pulau Pinang, Malaysia \\ *Corresponding author: chlatif@usm.my
}

Published online: 25 February 2018

To cite this article: Farooqui, U. R., Ahmad, A. L. \& Abdul Hameed, N. (2018). Influence of solvent and thickness variation on the performance of poly(vinylidene fluoride-cohexafluoropropylene) polymer membrane. J. Phys. Sci., 29(Supp. 1), 125-132, https://doi. org/10.21315/jps2018.29.s1.16

To link to this article: https://doi.org/10.21315/jps2018.29.s1.16

\begin{abstract}
This study involves the synthesis and characterisation of poly(vinylidene fuoride-co-hexafluoropropylene) (PVDF-HFP) polymer membrane by using breath figure method. The study was performed mainly to investigate the effect of solvent (acetone to NMP ratio of 100:0, 40:60, 50:50 and 60:40) and thickness (20 $\mu \mathrm{m}, 25 \mu \mathrm{m}, 30 \mu \mathrm{m}$ and $40 \mu \mathrm{m})$ variation on the performance of PVDF-HFP membrane. The different membrane samples were fabricated and characterised by different techniques such as scanning electron microscope (SEM), Fourier transform infrared (FTIR), porosity and mechanical strength. The mechanical stability of the membranes was mainly found to be thickness dependent, whereas the solvent variation has shown significant effect on the porosity, thickness and morphology of the prepared membranes. The highest porosity of $81.6 \%$ was obtained with acetone to NMP ratio of 40:60 compared to 53.4\% of pure acetone

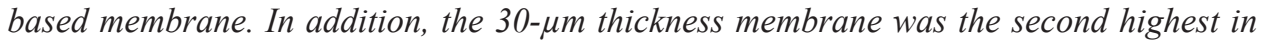
mechanical strength compared to 40- $\mu$ m membrane; however, its highest porosity of $70.7 \%$ has given it an added advantage and makes it a strong choice to consider as a porous membrane for various applications.
\end{abstract}

Keywords: PVDF-HFP membrane, solvent variation, thickness variation, poly(vinylidene fluoride, polymer membrane 


\section{INTRODUCTION}

Since their introduction, several fluoropolymers have been developed, modified and investigated, among which the poly(vinylidenefluoride co-hexafluoropropylene) (PVDF-HFP) has received much attraction; its amorphous HFP phase and crystalline VDF phase fulfils the requirement of many energy applications. ${ }^{1}$ Furthermore, its more hydrophobic nature compared to PVDF polymer makes it a suitable choice for membrane distillation and pervaporation. ${ }^{2,3}$ Additionally, its crystalline nature (VDF) provides mechanical strength and the amorphous nature (HFP) helps to hold the electrolyte in polymer electrolyte membranes mainly used in lithium batteries and fuel cells. ${ }^{4,5}$

The porous structure for better porosity and mechanical stability are among the most important parameters for many applications, especially in energy devices. However, these particular properties depend a lot on solvent selection, thickness and processing method. The number of techniques such as plasticiser extraction, electrospinning, breathe figure method, solvent casting and phase separation, etc. have been used for membrane preparation. ${ }^{6-9}$ In this work, the breathe figure method has been modified for the first time and used to synthesise and characterise the PVDF-HFP porous membrane. ${ }^{8}$ It will be interesting to see the effect of solvent and thickness variation on the performance of PVDF-HFP membrane. The prepared porous membrane can provide an effective alternate to several commercial membranes in energy storage applications.

\section{EXPERIMENTAL}

\subsection{Experimental Procedure}

The breathe figure method was used to fabricate the PVDF-HFP membrane. ${ }^{8}$ In short, $15 \mathrm{wt} \%$ of PVDF-HFP with acetone to NMP ratio (50:50) was cast with varying thickness such as $20 \mu \mathrm{m}, 25 \mu \mathrm{m}, 30 \mu \mathrm{m}$ and $40 \mu \mathrm{m}$. Afterward, the obtained optimum thickness of membrane was used to investigate the effect of solvent variation. For this, the varied ratio of acetone to NMP such as 100:00, 40:60, 50:50, and 60:40 was used to dissolve PVDF-HFP polymer. After mixing, a viscous and homogenous solution was obtained and was left overnight for proper degassing. After casting, the samples dried at room temperature (about 50\%-60\% $\mathrm{RH})$ for around $48 \mathrm{~h}$. The dried membranes were peeled out and stored in a dry cabinet for further usage. 


\subsection{Characterisation}

The structure and morphology of the prepared PVDF-HFP membranes were noticed by field emission electron microscope (FESEM, Zeiss Supra 35VP). The Fourier transform infrared (FTIR) characteristic peaks were obtained in a wavenumber range from $400-4000 \mathrm{~cm}^{-1}$ through Thermo Scientific Nicolet iS10 spectrometer by OMNIC software. The mechanical strength test was performed with a load cell of $10 \mathrm{kN}$ by using Instron 3366 (United States). The specimen of the membrane strip was cut as per ASTM-D882-10 standard. The viscosity of the different solvent mixture solutions was determined by Brookfield DV-III Ultra Programmable Rheometer, while porosity of the different membrane samples was determined by soaking membrane samples in $\mathrm{n}$-butanol for $2 \mathrm{~h}$ and weighing the sample weight before and after soaking. The equation used to calculate the porosity of the membrane sample is given by:

$$
\mathrm{P}=\mathrm{W}_{\text {wet }}-\mathrm{W}_{\text {dry }} /\left(\rho_{\mathrm{b}} \times \mathrm{V}_{\text {dry }}\right)
$$

where $\mathrm{W}_{\text {wet }}, \mathrm{W}_{\mathrm{dry}}, \rho_{\mathrm{b}}$ and $\mathrm{V}_{\mathrm{dry}}$ stand for weight of the butanol dipped membrane, weight of the dry membrane, density of butanol and volume of dry membrane, respectively.

\section{RESULTS AND DISCUSSION}

\subsection{FTIR Analysis}

Figure 1 shows the characteristic peaks obtained for the prepared PVDFHFP membrane through FTIR analysis. The $-\mathrm{CH}_{2}$ group has been observed at around $3030 \mathrm{~cm}^{-1}$, whereas, the characteristics obtained at $1401-1455 \mathrm{~cm}^{-1}$ are attributed to $-\mathrm{C}-\mathrm{F}-$ stretching. Moreover, the peak shown at $1174 \mathrm{~cm}^{-1}$ is assigned to $-\mathrm{CF}_{2}$ - group. Likewise, the peaks obtained near $1070 \mathrm{~cm}^{-1}, 874 \mathrm{~cm}^{-1}$ to $975 \mathrm{~cm}^{-1}$, $657 \mathrm{~cm}^{-1}$ and $838 \mathrm{~cm}^{-1}$ correspond to -C-C- skeletal vibration, vinylidene group and $-\mathrm{CH}_{2}$ - bonding respectively. Therefore, all the peaks including $761 \mathrm{~cm}^{-1}$ to $769 \mathrm{~cm}^{-1}\left(-\mathrm{CF}_{3^{-}}\right.$stretching) confirm the successful preparation of PVDF-HFP polymer membrane. In addition, FTIR spectra of PVDF-HFP membranes with highest porosity in both tests have presented; however, both the spectra haven't shown much difference compared to spectra of pure PVDF-HFP membrane. It shows that the solvent variation cannot alter the functional groups present in the polymer membrane. 


\subsection{Mechanical Strength}

The mechanical properties of PVDF-HFP membranes were investigated for different thickness and tabulated in Table 1. The results suggested that the increase in thickness improves the tensile strength and Young's modulus of the membrane. The highest tensile strength of $14 \mathrm{~Pa}$ has obtained with $40 \mu \mathrm{m}$ membrane. On the other hand, 20- $\mu \mathrm{m}$ membrane showed only 3.6 MPa and 129 of tensile strength and Young modulus respectively. Interestingly, membrane with thickness $30 \mu \mathrm{m}$ showed highest porosity of $70.7 \%$ which may be attributed to better porous structure at a particular thickness.

Furthermore, the better mechanical strength has attributed to higher membrane thickness. For this reason, NMP added membrane has also shown better mechanical stability compared to pure acetone membrane, as reported in Table 2. The pure acetone membrane showed tensile strength and Young modulus of 5.7 and 172 $\mathrm{MPa}$ respectively. Whereas, around 8.2 MPa tensile strength and $134 \mathrm{MPa}$ of Young modulus has been noticed with NMP added membrane. However, more than $60 \%$ NMP hasn't found suitable for breathe figure method as higher amount of non-volatile solvent cannot evaporate effectively and results in poor morphology of membrane. Subsequently, the acetone itself has been a very good solvent for PVDF-HFP porous membranes especially when prepared by breathe figure method; however, NMP is well known for its best compatibility with nanoparticles and inorganic fillers and its right combination with the volatile solvent will make a breathe figure method more flexible for future research.

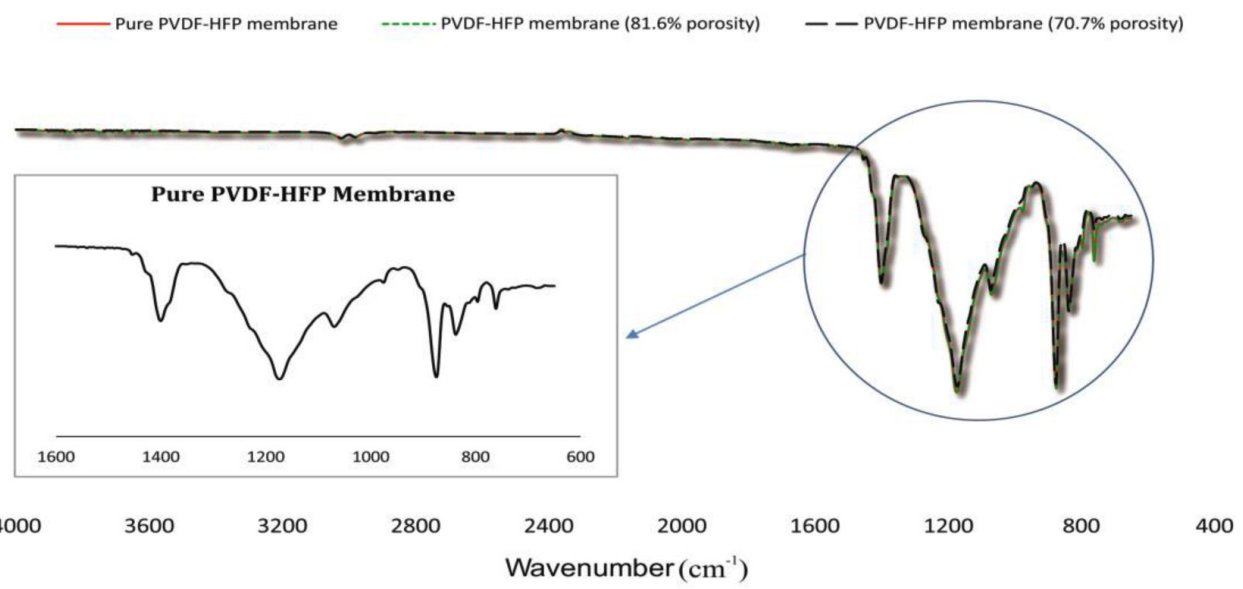

Figure 1: The FTIR characteristic peaks of different PVDF-HFP polymer membrane. 
Thus, the investigation shows that the highest tensile strength has been obtained with $40 \mu \mathrm{m}$ membrane due to higher thickness. However, almost an equal porosity was noticed with $30 \mu \mathrm{m}$ membrane sample as well. Nonetheless, the other membrane samples have also shown respectable mechanical stability too. In addition, the NMP addition to acetone solvent have shown a significant impact on the mechanical stability of PVDF-HFP membrane when cast by proposed technique.

Table 1: Effect of thickness variation on porosity and mechanical strength of PVDF-HFP membrane.

\begin{tabular}{ccccc}
\hline Sr. No & $\begin{array}{c}\text { Membrane samples }(15 \mathrm{wt} \%) \\
\text { (Acetone-NMP [1:1]) }\end{array}$ & $\begin{array}{c}\text { Porosity } \\
(\%)\end{array}$ & $\begin{array}{c}\text { Tensile strength } \\
(\mathrm{MPa})\end{array}$ & $\begin{array}{c}\text { Young's } \\
\text { modulus }\end{array}$ \\
\hline 1. & $20 \mu \mathrm{m}$ & 53.6 & 3.6 & 129 \\
2. & $25 \mu \mathrm{m}$ & 60.7 & 4.4 & 182 \\
3. & $30 \mu \mathrm{m}$ & 70.7 & 5.7 & 172 \\
4. & $40 \mu \mathrm{m}$ & 69.8 & 14.0 & 460 \\
\hline
\end{tabular}

\subsection{SEM Analysis}

As shown in Figure 2, each membrane has shown a considerable difference with solvent variation. The membrane samples with acetone to NMP ratio of 60:40 $(\mathrm{c}, \mathrm{g})$ and 100:00 (i, j) show lesser pores. However, porosity of both samples are still considerable for many applications. Also, a similar pattern has been observed with 40:60 (a, e) and 50:50 (b, f) membrane samples. The cross-section images $(e, f, g$ and $j$ ) also confirms the porous structure of all membranes.

Acetones are almost linear molecules. Hence, it leaves smaller voids on evaporation, and it also did not form a strong bonding with the host polymer due to lack of bonding groups. Therefore, the acetone molecules escape freely and leaves uniform pores upon evaporation, while NMP (a nonvolatile solvent) interacts well with the host polymer due to its amide group. The structure of the prepared membranes was also attributed to breathe figure method. When the cast membrane was allowed to dry in a natural environment with $50 \%-60 \% \mathrm{RH}$, the water droplets were generated on the surface of the membrane due to lower temperature caused by endothermic evaporation. ${ }^{8}$ The water droplets attract the PVDF-HFP molecules, which gathers around the droplets and assembled to provide a unique structure. 


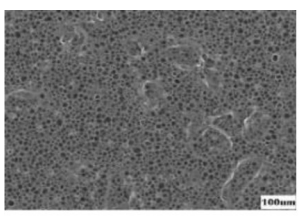

(a)

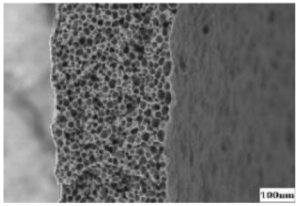

(e)

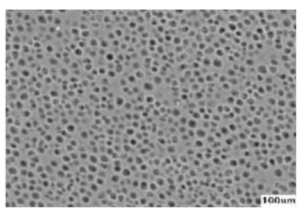

(i)

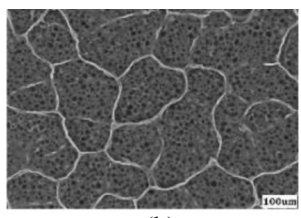

(b)

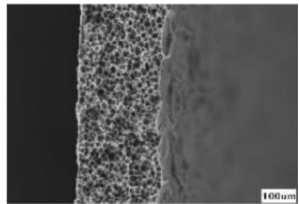

(f)

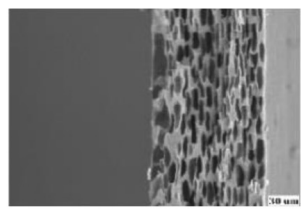

(j)

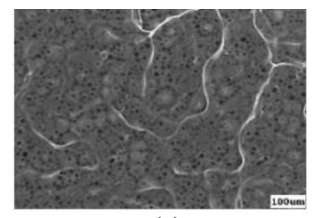

(c)

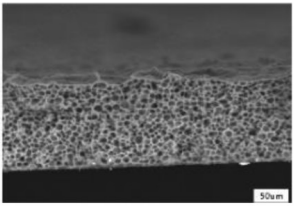

(g)

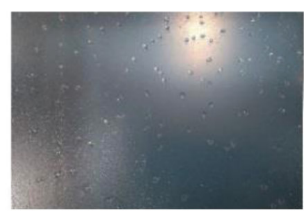

(k)

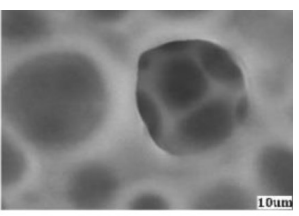

(d)

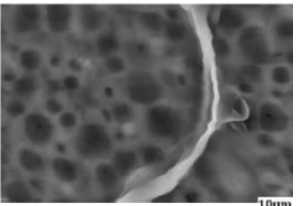

(h)

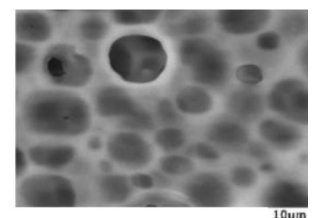

(1)

Figure 2: SEM images of PVDF-HFP membranes with different acetone to NMP solvent ratio; 40:60 (a, d and e); 50:50 (b, f and h); 60:40 (c, g); 100:00 (i, j and l); water droplets formed on surface $(\mathrm{k})$.

The SEM images confirm the morphological changes due to solvent variation with the host polymer. Even though most of the prepared membranes have shown good porosity, the membrane prepared with acetone to NMP ratio of 40:60 has shown uniform pores and resulted in highest porosity of $81.6 \%$. The highest porosity at a particular solvent mixture is attributed to the better interaction of acetone and NMP at particular ratio, which resulted in improved morphology of PVDF-HFP membrane.

Table 2: Effect of solvent variation on porosity, thickness and viscosity of PVDF-HFP membrane.

\begin{tabular}{cccccc}
\hline Sr. No & $\begin{array}{c}\text { Membrane samples } \\
(15 \mathrm{wt} \% \text { and } 30 \mu \mathrm{m}) \\
(\text { Acetone }: \text { NMP) }\end{array}$ & $\begin{array}{c}\text { Porosity } \\
(\%)\end{array}$ & $\begin{array}{c}\text { Obtained membrane } \\
\text { thickness }(\mu \mathrm{m})\end{array}$ & $\begin{array}{c}\text { Viscosity } \\
(\mathrm{Cp})\end{array}$ & $\begin{array}{c}\text { Tensile strength } \\
(\mathrm{MPa})\end{array}$ \\
\hline 1. & $100: 00$ & 53.4 & 30 & $75 \pm 5$ & - \\
2. & $40: 60$ & 81.6 & $65 \pm 10$ & $350 \pm 5$ & - \\
3. & $50: 50$ & 70.2 & 65 & $325 \pm 5$ & 5.7 \\
4. & $60: 40$ & 60.3 & $60 \pm 5$ & $300 \pm 5$ & - \\
5. & $00: 100$ & - & 75 & $500 \pm 5$ & 8.2 \\
\hline
\end{tabular}




\section{CONCLUSION}

The porous PVDF-HFP polymer membrane has been successfully synthesised through breath figure method. The solvent and thickness variation has shown significant impact on various factors of prepared membranes. The $40 \mu \mathrm{m}$ thickness membrane has resulted in highest tensile strength; however, the $30 \mu \mathrm{m}$ thickness membrane was more considerable one due to an equal porosity $(70.2 \%)$ of $40-\mu \mathrm{m}$ membrane. The PVDF-HFP membrane with acetone to NMP ratio of 40:60 has resulted in highest porosity of $81.6 \%$. In addition, NMP addition to the solvent has shown a substantial impact on the mechanical stability of membrane when prepared with the proposed technique. Therefore, the 40:60 acetone to NMP ratio has found suitable when cast with $30 \mu \mathrm{m}$ membrane with the proposed technique. However, this solvent combination and thickness variation study has just opened a new window for breath figure method and still needs an extensive research to optimise the performance of porous membrane.

\section{ACKNOWLEDGEMENTS}

This research work was financially supported by Fundamental Research Grant Scheme (203.PJKIMIA.6071355 and 203.PJKIMIA.6071334) offered by Ministry of Higher Education Malaysia and USM Fellowship provided by Universiti Sains Malaysia.

\section{REFERENCES}

1. Farooqui, U. R., Ahmad, A. L. \& Hamid, N. A. (2017). Effect of polyaniline (PANI) on poly(vinylidene fluoride-co-hexaflouropropylene) (PVDF-coHFP) polymer electrolyte membrane prepared by breath figure method. Polym. Test., 60, 124-131, https://doi.org/10.1016/j.polymertesting.2017. 03.012.

2. Feng, C. et al. (2006). Factors affecting pore structure and performance of poly(vinylidene fluoride-co-hexafluoro propylene) asymmetric porous membrane. J. Memb. Sci., 277, 55-64, https://doi.org/10.1016/j. memsci.2005.10.009.

3. Tian, X. et al. (2005). P(VDF-co-HFP) membrane for recovery of aroma compounds from aqueous solutions by pervaporation. J. Memb. Sci., 248, 109-117, https:// doi.org/10.1016/j.memsci.2004.10.003.

4. Pu, W. et al. (2006). Preparation of PVDF-HFP microporous membrane for Li-ion batteries by phase inversion. J. Memb. Sci., 272, 11-14, https://doi. org/10.1016/j.memsci.2005.12.038. 
5. Saikia, D. et al. (2004). Ionic conduction in P(VDF-HFP)/PVDF-(PC + DEC)-LiClO4 polymer gel electrolytes. Electrochim. Acta, 49, 2581-2589, https://doi.org/10.1016/j.electacta.2004.01.029.

6. Tarascon, J.-M. et al. (1996). Performance of Bellcore's plastic rechargeable Li-ion batteries. Solid State Ionics, 86, 49-54, https://dx.doi. org/10.1016/0167-2738(96)00330-X.

7. Zhang, S. S. (2007). A review on the separators of liquid electrolyte Liion batteries. J. Power Sour., 164, 351-364, https://doi.org/10.1016/j. jpowsour.2006.10.065.

8. Zhang, J. et al. (2014). Honeycomb-like porous gel polymer electrolyte membrane for lithium ion batteries with enhanced safety. Sci. Rep., 4, 6007, https://doi.org/10.1038/srep06007.

9. Choi, J.-W. et al. (2007) Rechargeable lithium/sulfur battery with suitable mixed liquid electrolytes. Electrochim. Acta, 52, 2075-2082, https://doi. org/10.1016/j.electacta.2006.08.016. 